\title{
Levantamento itossociológico de um fragmento de floresta estacional semidecidual no município de São João Evangelista
}

\author{
Alex do Nascimento Gonçalves ${ }^{1}$, João Barbosa dos Santos Neto ${ }^{1}$, Jadir Vieira da Silva ${ }^{2}$, Helen Cristina Santos \\ Machado $^{1}$, Aderlan Gomes da Silva ${ }^{3}$ \\ ${ }^{1}$ Tecnólogo em Silvicultura - Instituto Federal de Educação, Ciência e Tecnologia de Minas Gerais \\ - campus São João Evangelista-MG, alexgoncalves@yahoo.com.br \\ ${ }^{2}$ Mestrando em Ciência Florestal - Universidade Federal dos Vales do Jequitinhonha e Mucuri UFVJM, \\ jadirvsilva@yahoo.com.br \\ ${ }^{3}$ Professor Doutor em Fitopatologia do Instituto Federal de Educação, Ciência e Tecnologia de Minas Gerais - \\ campus São João Evangelista-MG, aderlan@yahoo.com.br
}

\section{RESUMO}

O objetivo deste trabalho foi conhecer a composição florística e avaliar a fitossociologia do estrato arbóreo, de um fragmento de Floresta Estacional Semidecidual, situado no município de São João Evangelista-MG. Utilizou-se a Amostragem Sistemática com alocação de 5 parcelas de área fixa de 40 por $25 \mathrm{~m}$, alocadas a cada $200 \mathrm{~m}$. Os parâmetros avaliados foram: Número de indivíduos (N), Área Basal (AB), Densidade Relativa (DR), Freqüência Relativa, Dominância Relativa, Índice de Valor de Cobertura, Índice de Valor de Importância (IVI), Posição Fitossociológica (PSR), Índice de Valor de Importância Ampliado (IVIA), índice de Diversidade de Shannon (H'), Índice de Equabilidade de Pielou (J'). Foram amostrados 427 indivíduos, pertencentes a 56 espécies. A espécie Mabea fistulfera apresentou maior valor para N (123 indivíduos), IVI $(19,94 \%)$ e PSR $(30,40)$. As famílias que apresentaram maior riqueza em espécies foram: Caesalpinaceae (4 espécies), seguida da Mimosaceae (3 espécies) e Annonaceae (2 espécies). A área basal total, foi de $5,447 \mathrm{~m}^{2}$, o H' obtido foi igual a 2,78, já o valor obtido para (J') foi de 0,69 , indicando tendência a uniformidade florística do componente arbóreo.

Palavras chave: Florística, Fitossociologia, Floresta semidecidual.

\section{Survey phytosociological of a fragment of semi deciduous forest in the city of São João Evangelista}

\begin{abstract}
The aim of this study was to evaluate the floristic composition and phytosociological of the tree layer, a fragment of semideciduous forest, located in the city of St. John the Evangelist-MG. We used systematic sampling with allocation of five permanent plots of 40 by $25 \mathrm{~m}, 200 \mathrm{~m}$ allocated to each The parameters evaluated were: number of individuals (N), Basal Area (BA), Relative Density (RD), Relative Frequency, Relative Dominance Index, covering value, Importance Value Index (IVI), phytosociological position (PSR), Importance Value Index Expanded (IVIA), Shannon Diversity Index (H') index of evenness (J'). We sampled 427 individuals belonging to 56 species. The species Mabea fistulfera showed higher value for $\mathrm{N}$ (123 individuals), IVI (19.94\%) and PSR (30,40). The families with highest species richness were Caesalpinaceae (4 species), followed by Mimosaceae ( 3 species) and Annonaceae ( 2 species). The basal area was
\end{abstract}


5.447 square feet, the $\mathrm{H}$ 'obtained was equal to 2.78 , since the value obtained for ( $\mathrm{J}$ ') was 0.69 , indicating a tendency for floristic uniformity of the tree component.

Key words: Floristic, Phytosociological, Semideciduous forest.

\section{INTRODUÇÃO}

Atualmente com o crescimento da população e conseqüentemente a necessidade cada vez maior de produção de energia, papel e outros produtos de origem florestal, a demanda por madeira tem aumentado, seja esta oriunda de áreas de reflorestamento ou de origem nativa. O aumento dessa demanda tem gerado um déficit de madeira (Scolforo \& Mello, 2006).

Os remanescentes de vegetação conhecidos como fragmentos florestais, advindos de vários anos de desmatamento progressivo, constituem hoje um dos maiores desafios para a conservação, pois abrigam uma diversidade biológica ainda não calculada e altamente ameaçada (Espirito-Santo \& Oliveira-Filho, 2001).

Segundo Almeida Júnior (1999) o grande consumo de madeira principalmente de origem nativa vem causando uma devastação desordenada de diversos ecossistemas naturais. A Floresta Atlântica é um desses ecossistemas que mais sofre com a ação antrópica, aumentando os riscos de desaparecimento de alguns fragmentos, tendo em vista o estádio de degradação e o reduzido tamanho em que os mesmos se encontram.

Em Minas Gerais, as Florestas Estacionais Semideciduais predominavam em uma vasta região do centro-sul e leste do estado, ocorrendo também na forma de manchas, principalmente na região do cerrado. Caracterizam-se por comunidades onde 20 a $50 \%$ dos indivíduos presentes no estrato superior perdem as folhas na estação seca. Esse tipo florestal está relacionado, em praticamente toda a sua área de ocorrência, a um clima de duas estações definidas, uma chuvosa e outra seca, ou então a uma acentuada variação térmica. Foram reconhecidas quatro formações: "Aluvial", "das Terras Baixas", "Submontana" e "Montana" a partir da relação entre latitude e altitude de sua área de ocorrência (Souza et al., 2007).

Atualmente, a cobertura vegetal de Minas Gerais está drasticamente reduzida a remanescentes esparsos. As formações florestais, assim como em outros estados brasileiros, não fugiram a essa realidade, que vem ocorrendo desde o período colonial (Oliveira-Filho \& Machado, 1993).

Um estudo realizado pelo CETEC (1983) concluiu que a floresta secundária substituiu, praticamente todas as florestas primárias existentes no estado, restando apenas pequenas manchas remanescentes, que correspondem a menos de $2 \%$ do território mineiro. As florestas semideciduais já ocuparam uma área bastante expressiva ao longo do estado de Minas Gerais (Leitao-Filho, 1982). Essas florestas apresentam uma alta diversidade florística e possuem uma flora arbórea bem estudada, quando comparada com a de outras formações vegetais (Leitão-Filho, 1992).

Levantamentos fitossociológicos vêm sendo realizados em florestas estacionais com o intuito de retratar a estrutura de determinados trechos de matas e de comparações de solo, clima, altitude e estágio sucessional (Oliveira-Filho et al., 1994, Schiavini, 1992).

Sabe-se que a vegetação brasileira, principalmente pela sua grande variedade, é ainda pouco conhecida, contudo estudos florísticos e da estrutura da vegetação surge como uma forma de aumentar o conhecimento da flora regional ou nacional e seus potenciais exploratórios entre outros aspectos do ponto de vista silvicultural (Silva Júnior, 2005).

O estudo da florística e da fitossociologia de uma floresta representa o passo inicial para o seu conhecimento, pois associado a sua estrutura e dinâmica pode-se construir 
uma base teórica que subsidie a conservação dos recursos genéticos, a conservação das áreas similares e a recuperação de áreas ou fragmentos florestais degradados, contribuindo substancialmente para o seu manejo (Vilela et al., 1993; Custodio Filho et al., 1994; Gilhuis, 1986).

Qualquer iniciativa de produção econômica da floresta passa também pelo levantamento florístico, que juntamente com os estudos fitossociológicos formam duas grandes barreiras a serem vencidas para formação de maciços florestais heterogêneos com espécies nativas arbóreas suscetíveis a planos de manejo ecológicos e economicamente rentáveis na exploração comercial (Paula et al., 1993). A complementariedade entre esses dois ramos da biologia dá suporte as interferências, subsidiando a conservação e recuperação (Vilela et al., 1993).

O presente trabalho teve como objetivo conhecer a composição florística e avaliar a fitossociologia das espécies arbóreas, de um fragmento de Floresta Estacional Semidecidual, situado no município de São João Evangelista-MG.

\section{MATERIAIS E MÉTODOS}

O remanescente florestal estudado encontra-se no Sítio São Nicolau Grande situado no município de São João Evangelista-MG, possui 9,5 hectares (ha) e está situado nas coordena-

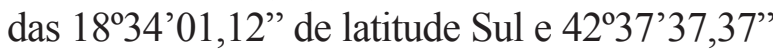
de longitude Oeste (Figura 1). A altitude média da área em estudo é de $710 \mathrm{~m}$, podendo atingir até $773 \mathrm{~m}$. A localização da área foi realizada com o auxílio de um aparelho digital de sistema de posicionamento global (GPS).

O clima é tropical de altitude com chuvas de verão e verões rigorosos, do tipo Cwa pelo sistema de Köppen (Ambientebrasil, 2008). A temperatura média é $20,1^{\circ} \mathrm{C}$ com mínima de $15^{\circ} \mathrm{C}$ e máxima de $26,1^{\circ} \mathrm{C}$, o índice pluviométrico anual é de 1081 mm (Procópio, 2008).

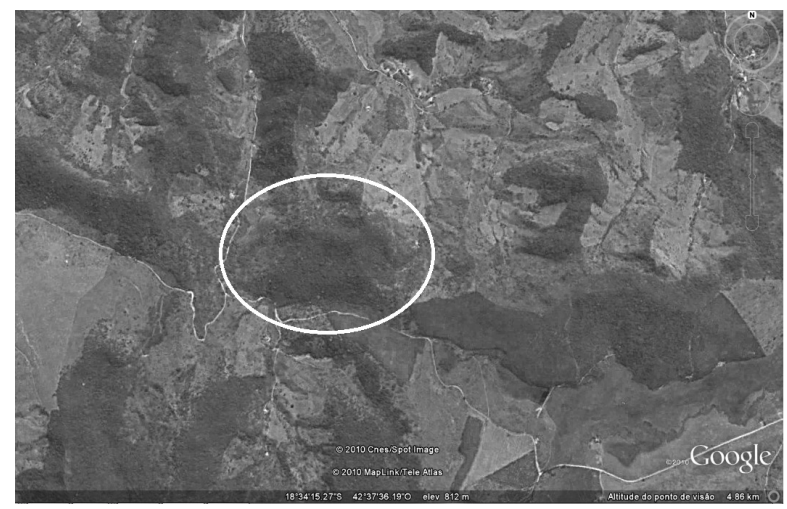

Figura 1. Área circundada representa o fragmento florestal em estudo.

Fonte: Googleearth, 2010.

Para a realização do levantamento fitossociológico utilizou-se a amostragem sistemática com alocação de 5 parcelas de área fixa de 40 por $25 \mathrm{~m}\left(1000 \mathrm{~m}^{2}\right)$, no sentido leste/oeste, alocadas a cada $200 \mathrm{~m}$, obtendo-se uma melhor representatividade da área. Porém houve a necessidade de se realizar a correção das mesmas, levando em consideração a declividade do terreno onde foram alocadas as parcelas, (Quadro 1).

Tabela 1. Números das parcelas e suas respectivas áreas corrigidas, de acordo com a declividade do terreno

\begin{tabular}{|c|c|}
\hline Número da Parcela & Área $(\mathrm{m} 2)$ \\
\hline 1 & 974,5 \\
\hline 2 & 945,3 \\
\hline 3 & 977,7 \\
\hline 4 & 977,7 \\
\hline 5 & 967,8 \\
\hline
\end{tabular}

Foram amostrados todos os indivíduos que apresentaram Diâmetro a Altura do Peito (DAP) maior ou igual a $7 \mathrm{~cm}$, de acordo com a PORTARIA No 191 , DE 16 DE SETEMBRO DE 2005 do Instituto Estadual de Florestas (IEF) (IEF, 2005). Das árvores amostradas foram medidos o DAP, utilizando a suta e estimada a altura com o auxilio de uma régua de madeira.

Foi feito um levantamento dendrológico das espécies amostradas no interior das 
parcelas sendo que o reconhecimento das espécies foi realizado de acordo com as características dendrológicas vegetativas, uma vez que na época de realização do estudo (Janeiro de 2009) não havia disponibilidade de órgãos reprodutivos.

Os parâmentos fitossociológicos, área basal, densidade, dominância, freqüência, valor de cobertura, valor de importância, posição sociológica, valor de importância ampliado, equabilidade e similaridade, foram calculados pelo Software Mata Nativa de autoria da CIENTEC (2006) os quais estão descritos em Scolforo (2006) e Soares (2006).

\section{Resultados e discussões}

No levantamento florístico e fitossociológico foram observadas 56 espécies, distribuídas em 26 fámilias (Tabela 2), sendo um total de 427 indivíduos (405 vivos e 22 mortos em pé). A não identificação de alguns indivíduos se deu devido à ausência de material vegetal reprodutivo (flor, fruto, semente, etc.) no período deste estudo, que impossibilitou a coleta para identificação.

As famílias que apresentaram maior riqueza em espécies foram: Caesalpinaceae (4 espécies), seguida da Mimosaceae (3 espécies) e Annonaceae ( 2 espécies); valores estes que se aproximaram de um levantamento fitossociológico feito em um componente arbóreo em Ubá - MG, onde as famílias que apresentaram maior riqueza, foram Caesalpinaceae (5 espécies), Mimosaceae (5 espécies) e Annonaceae (4 espécies) (Werneck et al., 2007).

Tabela 2. Relação das espécies e suas respectivas famílias, amostradas no levantamento fitossociológico

\begin{tabular}{|c|c|c|}
\hline Família & Nome Científico & Nome comum \\
\hline Annonaceae & $\begin{array}{c}\text { Xilopia sericea } \\
\text { Aspidosperma riedelii }\end{array}$ & $\begin{array}{l}\text { pimenteira } \\
\text { perobinha }\end{array}$ \\
\hline Buseraceae & Protium pallidum & amesca \\
\hline Caesalpinaceae & $\begin{array}{c}\text { Melanoxylon brauna } \\
\text { Cassia ferruginea } \\
\text { Apuleia leiocarpa } \\
\text { Pterogyne nitens }\end{array}$ & $\begin{array}{l}\text { braúna } \\
\text { canafístula } \\
\text { garapa } \\
\text { sucupira } \\
\end{array}$ \\
\hline Celastraceae & Austroplenckia populnea & marmelo \\
\hline Combretaceae & Terminalia brasiliensis & gema de ovo \\
\hline Euphorbiaceae & Mabea fistulifera & canudo de pito \\
\hline Fabaceae & Lonchocarpus Guillemineanus & ingá burro \\
\hline Lauraceae & Ocotea catharinensis & canela \\
\hline Malpighiaceae & Byrsonima stipulacea & murici \\
\hline Melastomataceae & Tibouchina candoleana & quaresminha \\
\hline Meliaceae & Guarea guidonia & marinheiro \\
\hline Mimosaceae & $\begin{array}{c}\text { Anadenanthera peregrina } \\
\text { Piptadenia gonoacantha } \\
\text { Plathymenia reticulata }\end{array}$ & $\begin{array}{l}\text { angico branco } \\
\text { jacaré } \\
\text { vinhático }\end{array}$ \\
\hline Myrtaceae & Psidium cattleianum & goiabeira \\
\hline Papilionoideae & $\begin{array}{l}\text { Dalbergia brasiliensis } \\
\text { Machaerium vestitum }\end{array}$ & $\begin{array}{c}\text { jacarandá } \\
\text { jacarandá branco }\end{array}$ \\
\hline Proteaceae & Euplassa incana & carvalhinho \\
\hline Rubiaceae & Calycophyllum spruceanum & mulatinho \\
\hline Rutaceae & Zantoxylum riedelianum & mamica de porca \\
\hline Styracaceae & Styrax ferrugineus & pindaíba \\
\hline Tiliaceae & $\begin{array}{c}- \\
\text { Leuhea grandifolia }\end{array}$ & $\begin{array}{c}- \\
\text { açoita cavalo }\end{array}$ \\
\hline \multirow[t]{3}{*}{ Verbenaceae } & Vitex montevidensis & azeitona \\
\hline & & morta \\
\hline & & $\mathrm{Ni}^{1}(1 \text { a } 28)^{*}$ \\
\hline
\end{tabular}

* Espécies não identificadas. 
Com relação ao número de indivíduos, as dez espécies de maior densidade relativa representaram $88,39 \%$ do total de indivíduos amostrados, com Mabea fistulifera ocupando a primeira posição $(28,81 \%)$ seguida de Plathymenia reticulata, Byrsonima stipulacea, Xilopia sericea, Terminalia brasiliensis, Protium pallidum, Lonchocarpus Guillemineanus, Melanoxylon braúna, Apuleia leiocarpa e Anadenanthera peregrina. As espécies mortas aparecem em sexto lugar no que diz respeito ao número de indivíduos. Isso pode ser explicado pela idade avançada da qual os indivíduos possuem, pelo ataque de organismos decompositores e outros fatores extrínsecos, como o clima.

Observa-se na Tabela 3, as espécies amostradas que apresentaram os maiores índices de valor de importância (IVI): $M a$ bea fistulifera (Canudo de pito) 19,94\%, Plathymenia reticulata (Vinhático) 9,51\%, Byrsonima stipulaceae (Murici) 7,72\%, Xilopia sericea (Pimenteira) 7,37\%, Terminalia brasiliensis (Gema de ovo) 6,65\%, Protium pallidum (Amesca) 1,91\%, Lonchocarpus guillemineanus (Ingá burro) 1,87\%, Melanoxylon brauna (Braúna) 1,82\%, Apuleia leiocarpa (Garapa) 1,72\% e Anadenanthera peregrina (Angico branco) 1,71\%.

Entre as espécies amostradas, a $\mathrm{Me}$ lanoxylon brauna, apresentou seis indivíduos ficando em nono lugar, porém estes indivíduos foram amostrados em uma única parcela, indicando baixa ocorrência da espécie na área. Isto pode ser explicado devido ao fato de ser uma espécie bastante explorada por apresentar madeira de excelente qualidade e alta durabilidade natural (Paes, 2005). A espécie Mabea fistulifera (Canudo de pito), apresentou a maior ocorrência, totalizando um contingente de 123 indivíduos. Foram amostradas 22 espécies $(39,29 \%)$ com um único indivíduo, destacando-se entre essas a presença de Zantoxylum riedelianum, Guarea guidonia e Calycophyllum spruceanum (Tabela 3).

Em relação a área basal, o valor obtido foi de $5,447 \mathrm{~m}^{2}$, já no estudo da Estrutura Fitossociológica de um Remanescente de Floresta Estacional Semidecidual da Fazenda Experimental do Glória, Uberlândia, $\mathrm{MG}$ realizado por Souza Neto, et al. (2007) a área basal foi $26,19 \mathrm{~m}^{2}$. A discrepância entre os dados se deu devido a baixa classe diamétrica da maioria das árvores amostradas (Figura 2).



Figura 2: Densidade absoluta (Número de indivíduos por hectare) por classe diamétrica para todas as espécies do fragmento estudado. 
Levantamento itossociológico de um fragmento de floresta

estacional semidecidual no município de São João Evangelista

Tabela 3. Estrutura horizontal: Distribuição do(s) parâmetro(s) N, AB, DR, FR, DoR, VC(\%), IVI (\%).

\begin{tabular}{|c|c|c|c|c|c|c|c|}
\hline Nome Ciêntífico & $\mathrm{N}$ & $\mathrm{AB}$ & $\overline{\mathrm{DR}}$ & FR & DoR & $\mathrm{VC}(\%)$ & IVI (\%) \\
\hline Mabea fistulifera & 123 & 1,361 & 28,8 & 6,0 & 25,0 & 26,89 & 19,9 \\
\hline Plathymenia reticulata & 43 & 0,744 & 10,1 & 4,8 & 13,7 & 11,86 & 9,51 \\
\hline Byrsonima stipulacea & 37 & 0,462 & 8,67 & 6,0 & 8,47 & 8,57 & 7,72 \\
\hline Xilopia sericea & 42 & 0,340 & 9,84 & 6,0 & 6,24 & 8,04 & 7,37 \\
\hline Terminalia brasiliensis & 43 & 0,407 & 10,1 & 2,4 & 7,47 & 8,77 & 6,65 \\
\hline Morta & 22 & 0,290 & 5,15 & 6,0 & 5,31 & 5,23 & 5,50 \\
\hline Protium pallidum & 9 & 0,132 & 2,11 & 1,2 & 2,42 & 2,26 & 1,91 \\
\hline Lonchocarpus Guillemineanus & 4 & 0,058 & 0,94 & 3,6 & 1,06 & 1,00 & 1,87 \\
\hline Melanoxylon brauna & 6 & 0,155 & 1,41 & 1,2 & 2,84 & 2,12 & 1,82 \\
\hline Apuleia leiocarpa & 6 & 0,073 & 1,41 & 2,4 & 1,34 & 1,37 & 1,72 \\
\hline Anadenanthera peregrina & 2 & 0,189 & 0,47 & 1,2 & 3,46 & 1,97 & 1,71 \\
\hline Aspidosperma riedelii & 7 & 0,096 & 1,64 & 1,2 & 1,76 & 1,70 & 1,54 \\
\hline Leuhea grandifolia & 7 & 0,087 & 1,64 & 1,2 & 1,60 & 1,62 & 1,48 \\
\hline Piptadenia gonoacantha & 3 & 0,063 & 0,70 & 2,4 & 1,16 & 0,93 & 1,42 \\
\hline Styrax ferrugineus & 2 & 0,045 & 0,47 & 2,4 & 0,82 & 0,65 & 1,23 \\
\hline Pterogyne nitens & 3 & 0,017 & 0,70 & 2,4 & 0,31 & 0,51 & 1,14 \\
\hline Machaerium vestitum & 5 & 0,045 & 1,17 & 1,2 & 0,82 & 0,99 & 1,06 \\
\hline Tibouchina candoleana & 4 & 0,052 & 0,94 & 1,2 & 0,95 & 0,94 & 1,03 \\
\hline Ni19 & 2 & 0,077 & 0,47 & 1,2 & 1,41 & 0,94 & 1,03 \\
\hline $\mathrm{Ni3}$ & 2 & 0,010 & 0,47 & 2,4 & 0,18 & 0,33 & 1,02 \\
\hline Ni12 & 2 & 0,057 & 0,47 & 1,2 & 1,05 & 0,76 & 0,91 \\
\hline Zantoxylum riedelianum & 1 & 0,068 & 0,23 & 1,2 & 1,24 & 0,74 & 0,89 \\
\hline Ni6 & 3 & 0,040 & 0,70 & 1,2 & 0,73 & 0,72 & 0,88 \\
\hline $\mathrm{Ni} 2$ & 3 & 0,037 & 0,70 & 1,2 & 0,68 & 0,69 & 0,86 \\
\hline $\mathrm{Ni} 4$ & 2 & 0,050 & 0,47 & 1,2 & 0,92 & 0,69 & 0,86 \\
\hline Nil8 & 3 & 0,036 & 0,70 & 1,2 & 0,65 & 0,68 & 0,85 \\
\hline Nil & 3 & 0,028 & 0,70 & 1,2 & 0,51 & 0,61 & 0,81 \\
\hline Austroplenckia populnea & 2 & 0,033 & 0,47 & 1,2 & 0,60 & 0,54 & 0,76 \\
\hline Nil6 & 2 & 0,032 & 0,47 & 1,2 & 0,58 & 0,52 & 0,75 \\
\hline $\mathrm{Ni} 21$ & 2 & 0,030 & 0,47 & 1,2 & 0,56 & 0,51 & 0,74 \\
\hline Cassia ferruginea & 3 & 0,015 & 0,70 & 1,2 & 0,27 & 0,48 & 0,72 \\
\hline Ni10 & 1 & 0,037 & 0,23 & 1,2 & 0,68 & 0,45 & 0,70 \\
\hline Dalbergia brasiliensis & 2 & 0,022 & 0,47 & 1,2 & 0,40 & 0,44 & 0,69 \\
\hline $\mathrm{Ni} 27$ & 1 & 0,035 & 0,23 & 1,2 & 0,63 & 0,43 & 0,69 \\
\hline Guarea guidonia & 1 & 0,028 & 0,23 & 1,2 & 0,51 & 0,37 & 0,65 \\
\hline Ni26 & 1 & 0,027 & 0,23 & 1,2 & 0,50 & 0,37 & 0,65 \\
\hline Psidium cattleianum & 2 & 0,012 & 0,47 & 1,2 & 0,23 & 0,35 & 0,63 \\
\hline Euplassa incana & 2 & 0,011 & 0,47 & 1,2 & 0,20 & 0,33 & 0,62 \\
\hline Ni8 & 2 & 0,010 & 0,47 & 1,2 & 0,18 & 0,33 & 0,62 \\
\hline Ni20 & 1 & 0,020 & 0,23 & 1,2 & 0,37 & 0,30 & 0,60 \\
\hline Nill & 1 & 0,014 & 0,23 & 1,2 & 0,26 & 0,25 & 0,57 \\
\hline Ni15 & 1 & 0,014 & 0,23 & 1,2 & 0,26 & 0,25 & 0,57 \\
\hline Nil4 & 1 & 0,011 & 0,23 & 1,2 & 0,20 & 0,22 & 0,55 \\
\hline $\mathrm{Ni} 24$ & 1 & 0,012 & 0,23 & 1,2 & 0,21 & 0,22 & 0,55 \\
\hline Vitex montevidensis & 1 & 0,010 & 0,23 & 1,2 & 0,17 & 0,20 & 0,54 \\
\hline Ni17 & 1 & 0,009 & 0,23 & 1,2 & 0,16 & 0,20 & 0,53 \\
\hline Ni9 & 1 & 0,008 & 0,23 & 1,2 & 0,15 & 0,19 & 0,53 \\
\hline Ocotea catharinensis & 1 & 0,006 & 0,23 & 1,2 & 0,12 & 0,18 & 0,52 \\
\hline Ni13 & 1 & 0,006 & 0,23 & 1,2 & 0,12 & 0,18 & 0,52 \\
\hline Calycophyllum spruceanum & 1 & 0,005 & 0,23 & 1,2 & 0,08 & 0,16 & 0,51 \\
\hline Ni28 & 1 & 0,005 & 0,23 & 1,2 & 0,09 & 0,16 & 0,51 \\
\hline $\mathrm{Ni} 22$ & 1 & 0,004 & 0,23 & 1,2 & 0,08 & 0,16 & 0,51 \\
\hline Ni23 & 1 & 0,004 & 0,23 & 1,2 & 0,08 & 0,16 & 0,51 \\
\hline $\mathrm{Ni} 5$ & 1 & 0,005 & 0,23 & 1,2 & 0,10 & 0,16 & 0,51 \\
\hline Ni7 & 1 & 0,006 & 0,23 & 1,2 & 0,10 & 0,17 & 0,51 \\
\hline $\mathrm{Ni} 25$ & 1 & 0,004 & 0,23 & 1,2 & 0,07 & 0,15 & 0,50 \\
\hline *** Total & 427 & 5,447 & 100,00 & 100,0 & 100,00 & 100,00 & 100,00 \\
\hline
\end{tabular}

Em que: $\mathrm{N}=$ número de indivíduos, $\mathrm{AB}=$ área basal, $\mathrm{DR}=$ densidade relativa, $\mathrm{FR}=$ frequencia relativa, $\mathrm{DoR}=$ dominância relativa, $\mathrm{VC}=$ valor de cobertura e IVI = índice de valor de importância. 
O índice de diversidade de Shannon (H') obtido foi igual a 2,78, inferior ao valor estimado por Guimarães (2008), que foi igual a 3,93 no trabalho realizado no Fragmento de Floresta Estacional Semidecidual Montana no Município de Poços de Caldas-MG, indicando que o fragmento estudado apresentou menor diversidade florística quando comparado ao trabalho citado.

O valor obtido para equabilidade ( $\left.\mathrm{J}^{\prime}\right)$ foi de 0,69 , indicando tendência à uniformidade da florística do componente arbóreo, ou seja, indica que 69\% da diversidade máxima teórica foi contemplada na amostragem realizada, tendendo ainda à igualdade, a distribuição do número de indivíduos pelas espécies, demonstrando uma alta heterogeneidade do componente arbóreo.

A floresta apresentou dossel irregular, onde foram amostrados indivíduos com altura mínima de 2,20 m (árvore morta) e máxima de 16,65 m (Plathymenia reticulata). O total de indivíduos amostrados no estrato inferior foi 59 , com altura inferior a 5,95m; no estrato médio amostrou-se 326 indivíduos com altura variando entre 5,95 a $10,20 \mathrm{~m}$; já o estrato superior apresentou 42 indivíduos com altura superior a 10,20. Dentre as espécies amostradas as que apresentaram maiores médias de altura foram: Anadenanthera peregrina $(16,5 \mathrm{~m})$, Zantoxylum riedelianum $(16,5 \mathrm{~m}) \mathrm{e}$ Styrax ferrugineus $(12,44 \mathrm{~m})$ (Tabela 4$)$.

A posição sociológica relativa (PSR) encontrada para a espécie Mabea fistulifera (canudo de pito) apresentou maior valor $(30,40)$, quando comparado aos valores das demais espécies. Isso se deve ao fato de que a espécie apresentou grande número de indivíduos, principalmente no estrato médio (100 indivíduos), e estar presente também nos outros dois estratos.
Esta distribuição de alturas para o canudo de pito provavelmente seja conseqüência direta de intervenções antrópicas, como a abertura de clareiras devido a extração da madeira para usos domésticos de pequenos agricultores do entorno do fragmento estudado, posteriormente interferindo no número de indivíduos presentes no estrato superior (6 indivíduos). Por ser uma espécie pioneira, a abertura de clareiras favoreceu um rápido desenvolvimento, porém o dossel formado por esses indivíduos interferiu no desenvolvimento dos mesmos no estrato inferior (17 indivíduos).

As espécies Byrsonima stipulacea (murici) e Xilopia sericea (pimenteira) apresentaram valores de (PSR) bem próximos 9,11 e 9,79 respectivamente. Embora o Byrsonima stipulacea possua maior IVI\% que Xilopia sericea, sua PSR é menor. Isso devido à Xilopia sericea estar melhor distribuída entre os estratos, indicando que os indivíduos do estrato inferior formam um estoque da espécie que tem conseguido suprir os demais estratos. Outro aspecto para a melhor distribuição da Xilopia sericea está relacionado à forma florestal da espécie que apresenta fuste único e retilíneo, ocorrendo um incremento aparentemente preferencial em altura em detrimento do diâmetro. Já o Byrsonima stipulacea, possui a copa com maior quantidade de galhos e um incremento aparentemente maior em diâmetro.

As duas espécies apresentam poucos indivíduos no estrato inferior se comparadas ao Plathymenia reticulata (vinhático) com PSR igual a 7,64, o que pode ser um indicativo do que a regeneração desta espécie esteja sendo favorecida pelas condições presentes no fragmento florestal atualmente. 
Levantamento itossociológico de um fragmento de floresta

estacional semidecidual no município de São João Evangelista

Tabela 4: Estrutura Vertical - Posição Sociológica - Distribuição do(s) parâmetro(s) N, DoR, PSR.

\begin{tabular}{|c|c|c|c|c|c|c|c|c|c|}
\hline \multirow{2}{*}{ Nome Vulgar } & \multirow[b]{2}{*}{ IVI } & \multirow[b]{2}{*}{ IVI \% } & \multirow[b]{2}{*}{$\mathrm{VC} \%$} & \multirow[b]{2}{*}{ Par. } & \multicolumn{3}{|c|}{ Classes de altura } & \multirow[b]{2}{*}{ Total } & \multirow[b]{2}{*}{ PSR } \\
\hline & & & & & $\mathrm{H}<5,95$ & $5,95<=\mathrm{H}<0,20$ & $\mathrm{H}>=10,20$ & & \\
\hline \multirow{2}{*}{ Mabea fistulifera } & 59,81 & 19,90 & 26,90 & $\mathrm{~N}$ & 17,00 & 100,00 & 6,00 & 123,00 & 30,40 \\
\hline & & & & DoR & 24,74 & 29,58 & 12,04 & 25,00 & \\
\hline \multirow{2}{*}{ Plathymenia reticulata } & 28,54 & 9,51 & 11,90 & $\mathrm{~N}$ & 11,00 & 23,00 & 9,00 & 43,00 & 7,64 \\
\hline & & & & DoR & 16,59 & 8,29 & 27,81 & 13,70 & \\
\hline Byrsonima stipulacea & 23,16 & 7,72 & 8,57 & $\mathrm{~N}$ & 5,00 & 30,00 & 2,00 & 37,00 & 9,11 \\
\hline & & & & DoR & 10,58 & 10,58 & 1,78 & 8,47 & \\
\hline Xilopia sericea & 22,11 & 7,37 & 8,04 & $\mathrm{~N}$ & 4,00 & 32,00 & 6,00 & 42,00 & 9,79 \\
\hline & & & & DoR & 6,11 & 6,92 & 4,38 & 6,24 & \\
\hline Terminalia brasiliensis & 19,95 & 6,65 & 8,77 & $\mathrm{~N}$ & 5,00 & 38,00 & 0,00 & 43,00 & 11,40 \\
\hline & & & & DoR & 13,40 & 9,39 & 0,00 & 7,47 & \\
\hline Morta & 16,49 & 5,50 & 5,23 & $\mathrm{~N}$ & 7,00 & 14,00 & 1,00 & 22,00 & 4,50 \\
\hline & & & & DoR & 13,91 & 5,70 & 1,27 & 5,31 & \\
\hline Protium pallidum & 5,73 & 1,91 & 2,26 & $\mathrm{~N}$ & 1,00 & 8,00 & 0,00 & 9,00 & 2,39 \\
\hline & & & & DoR & 1,26 & 3,41 & 0,00 & 2,42 & \\
\hline Lonchocarpus Guillemineanus & 5,61 & 1,87 & 1 & $\mathrm{~N}$ & 0,00 & 3,00 & 1,00 & 4,00 & 0,91 \\
\hline & & & & DoR & 0,00 & 0,97 & 1,67 & 1,06 & \\
\hline Melanoxylon brauna & 5,45 & 1,82 & 2,12 & $\mathrm{~N}$ & 0,00 & 3,00 & 3,00 & 6,00 & 0,99 \\
\hline & & & & DoR & 0,00 & 0,87 & 9,38 & 2,84 & \\
\hline Apuleia leiocarpa & 5,15 & 1,72 & 1,37 & $\mathrm{~N}$ & 1,00 & 3,00 & 2,00 & 6,00 & 1,01 \\
\hline & & & & DoR & 2,21 & 0,64 & 3,00 & 1,34 & \\
\hline Anadenanthera peregrina & 5,14 & 1,71 & 1,97 & $\mathrm{~N}$ & 0,00 & 0,00 & 2,00 & 2,00 & 0,08 \\
\hline & & & & DoR & 0,00 & 0,00 & 14,46 & 3,46 & \\
\hline Aspidosperma riedelii & 4,61 & 1,54 & 1,70 & $\mathrm{~N}$ & 1,00 & 6,00 & 0,00 & 7,00 & 1,81 \\
\hline & & & & DoR & 1,40 & 2,43 & 0,00 & 1,76 & \\
\hline Leuhea grandifolia & 4,44 & 1,48 & 1,62 & $\mathrm{~N}$ & 0,00 & 7,00 & 0,00 & 7,00 & 2,05 \\
\hline & & & & DoR & 0,00 & 2,35 & 0,00 & 1,60 & \\
\hline Piptadenia gonoacantha & 4,27 & 1,42 & 0,93 & $\mathrm{~N}$ & 0,00 & 2,00 & 1,00 & 3,00 & 0,62 \\
\hline & & & & DoR & 0,00 & 0,74 & 2,76 & 1,16 & \\
\hline Styrax ferrugineus & 3,70 & 1,23 & 0,65 & $\mathrm{~N}$ & 0,00 & 1,00 & 1,00 & 2,00 & 0,33 \\
\hline & & & & DoR & 0,00 & 0,66 & 1,57 & 0,82 & \\
\hline Pterogyne nitens & 3,43 & 1,14 & 0,51 & $\mathrm{~N}$ & 1,00 & 2,00 & 0,00 & 3,00 & 0,64 \\
\hline & & & & DoR & 0,93 & 0,35 & 0,00 & 0,31 & \\
\hline Machaerium vestitum & 3,19 & 1,06 & 0,99 & $\mathrm{~N}$ & 0,00 & 5,00 & 0,00 & 5,00 & 1,46 \\
\hline & & & & DoR & 0,00 & 1,21 & 0,00 & 0,82 & \\
\hline Tibouchina candoleana & 3,09 & 1,03 & 0,94 & $\mathrm{~N}$ & 0,00 & 3,00 & 1,00 & 4,00 & 0,91 \\
\hline & & & & DoR & 0,00 & 1,27 & 0,39 & 0,95 & \\
\hline Ni19 & 3,08 & 1,03 & 0,94 & $\mathrm{~N}$ & 0,00 & 1,00 & 1,00 & 2,00 & 0,33 \\
\hline & & & & DoR & 0,00 & 1,00 & 3,05 & 1,41 & \\
\hline Ni3 & 3,06 & 1,02 & 0,33 & $\mathrm{~N}$ & 1,00 & 1,00 & 0,00 & 2,00 & 0,35 \\
\hline & & & & DoR & 0,96 & 0,15 & 0,00 & 0,18 & \\
\hline Ni12 & 2,72 & 0,91 & 0,76 & $\mathrm{~N}$ & 0,00 & 1,00 & 1,00 & 2,00 & 0,33 \\
\hline & & & & DoR & 0,00 & 0,49 & 2,99 & 1,05 & \\
\hline Zantoxylum riedelianum & 2,68 & 0,89 & 0,74 & $\mathrm{~N}$ & 0,00 & 0,00 & 1,00 & 1,00 & 0,04 \\
\hline & & & & DoR & 0,00 & 0,00 & 5,19 & 1,24 & \\
\hline Ni6 & 2,64 & 0,88 & 0,72 & $\mathrm{~N}$ & 0,00 & 3,00 & 0,00 & 3,00 & 0,88 \\
\hline & & & & DoR & 0,00 & 1,08 & 0,00 & 0,73 & \\
\hline $\mathrm{Ni} 2$ & 2,59 & 0,86 & 0,69 & $\mathrm{~N}$ & 0,00 & 2,00 & 0,00 & 3,00 & 0,64 \\
\hline & & & & DoR & 1,54 & 0,82 & 0,00 & 0,68 & \\
\hline $\mathrm{Ni4}$ & 2,59 & 0,86 & 0,69 & $\mathrm{~N}$ & 0,00 & 0,00 & 2,00 & 2,00 & 0,08 \\
\hline & & & & DoR & 0,00 & 0,00 & 3,83 & 0,92 & \\
\hline Ni18 & 2,56 & 0,85 & 0,68 & $\mathrm{~N}$ & 0,00 & 3,00 & 0,00 & 3,00 & 0,88 \\
\hline & & & & DoR & 0,00 & 0,96 & 0,00 & 0,65 & \\
\hline Nil & 2,42 & 0,81 & 0,61 & $\mathrm{~N}$ & 0,00 & 3,00 & 0,00 & 3,00 & 0,88 \\
\hline & & & & DoR & 0,00 & 0,75 & 0,00 & 0,51 & \\
\hline Austroplenckia populnea & 2,28 & 0,76 & 0,54 & $\mathrm{~N}$ & 0,00 & 2,00 & 0,00 & 2,00 & 0,58 \\
\hline & & & & DoR & 0,00 & 0,89 & 0,00 & 0,60 & \\
\hline Ni16 & 2,25 & 0,75 & 0,52 & $\mathrm{~N}$ & 0,00 & 2,00 & 0,00 & 2,00 & 0,58 \\
\hline & & & & DoR & 0,00 & 0,85 & 0,00 & 0,58 & \\
\hline $\mathrm{Ni} 21$ & 2,23 & 0,74 & 0,51 & $\mathrm{~N}$ & 1,00 & 0,00 & 1,00 & 2,00 & 0,09 \\
\hline & & & & DoR & 2,00 & 0,00 & 1,64 & 0,56 & \\
\hline Cassia ferruginea & 2,17 & 0,72 & 0,48 & $\mathrm{~N}$ & 0,00 & 3,00 & 0,00 & 3,00 & 0,88 \\
\hline & & & & DoR & 0,00 & 0,39 & 0,00 & 0,27 & \\
\hline Ni10 & 2,12 & 0,70 & 0,45 & $\mathrm{~N}$ & 0,00 & 0,00 & 1,00 & 1,00 & 0,04 \\
\hline & & & & DoR & 0,00 & 0,00 & 2,82 & 0,68 & \\
\hline Dalbergia brasiliensis & 2,08 & 0,69 & 0,44 & $\mathrm{~N}$ & 1,00 & 1,00 & 0,00 & 2,00 & 0,35 \\
\hline & & & & DoR & 1,31 & 0,44 & 0,00 & 0,40 & \\
\hline
\end{tabular}

Continua... 


\begin{tabular}{|c|c|c|c|c|c|c|c|c|c|}
\hline & & & & & & Classes de altur: & & & \\
\hline Nome Vulgar & IVI & IVI \% & VC \% & Par. & $\mathrm{H}<5,95$ & $5,95<=\mathrm{H}<0,20$ & $\mathrm{H}>=10,20$ & Total & PSR \\
\hline Ni27 & 2,07 & 0,69 & 0,43 & $\mathrm{~N}$ & 0,00 & 1,00 & 0,00 & 1,00 & 0,29 \\
\hline & & & & DoR & 0,00 & 0,93 & 0,00 & 0,63 & \\
\hline Guarea guidonia & 1,95 & 0,65 & 0,37 & $\mathrm{~N}$ & 0,00 & 1,00 & 0,00 & 1,00 & 0,29 \\
\hline & & & & DoR & 0,00 & 0,75 & 0,00 & 0,51 & \\
\hline $\mathrm{Ni26}$ & 1,94 & 0,65 & 0,37 & $\mathrm{~N}$ & 0,00 & 1,00 & 0,00 & 1,00 & 0,29 \\
\hline & & & & DoR & 0,00 & 0,73 & 0,00 & 0,50 & \\
\hline Psidium cattleianum & 1,90 & 0,63 & 0,35 & $\mathrm{~N}$ & 1,00 & 1,00 & 0,00 & 2,00 & 0,35 \\
\hline & & & & DoR & 1,91 & 0,10 & 0,00 & 0,23 & \\
\hline Euplassa incana & 1,87 & 0,62 & 0,33 & $\mathrm{~N}$ & 0,00 & 2,00 & 0,00 & 2,00 & 0,58 \\
\hline & & & & DoR & 0,00 & 0,30 & 0,00 & 0,20 & \\
\hline $\mathrm{Ni} 8$ & 1,86 & 0,62 & 0,33 & $\mathrm{~N}$ & 0,00 & 2,00 & 0,00 & 2,00 & 0,58 \\
\hline & & & & DoR & 0,00 & 0,27 & 0,00 & 0,18 & \\
\hline $\mathrm{Ni20}$ & 1,81 & 0,60 & 0,30 & $\mathrm{~N}$ & 0,00 & 1,00 & 0,00 & 1,00 & 0,29 \\
\hline & & & & DoR & 0,00 & 0,55 & 0,00 & 0,37 & \\
\hline Ni11 & 1,70 & 0,57 & 0,25 & $\mathrm{~N}$ & 0,00 & 1,00 & 0,00 & 1,00 & 0,29 \\
\hline & & & & DoR & 0,00 & 0,38 & 0,00 & 0,26 & \\
\hline Ni15 & 1,70 & 0,57 & 0,25 & $\mathrm{~N}$ & 0,00 & 1,00 & 0,00 & 1,00 & 0,29 \\
\hline & & & & DoR & 0,00 & 0,38 & 0,00 & 0,26 & \\
\hline Ni24 & 1,65 & 0,55 & 0,22 & $\mathrm{~N}$ & 0,00 & 1,00 & 0,00 & 1,00 & 0,29 \\
\hline & & & & DoR & 0,00 & 0,32 & 0,00 & 0,21 & \\
\hline Ni14 & 1,64 & 0,55 & 0,22 & $\mathrm{~N}$ & 0,00 & 1,00 & 0,00 & 1,00 & 0,29 \\
\hline & & & & DoR & 0,00 & 0,30 & 0,00 & 0,20 & \\
\hline Vitex montevidensis & 1,61 & 0,54 & 0,20 & $\mathrm{~N}$ & 0,00 & 1,00 & 0,00 & 1,00 & 0,29 \\
\hline & & & & DoR & 0,00 & 0,26 & 0,00 & 0,17 & \\
\hline Ni17 & 1,60 & 0,53 & 0,20 & $\mathrm{~N}$ & 0,00 & 1,00 & 0,00 & 1,00 & 0,29 \\
\hline & & & & DoR & 0,00 & 0,23 & 0,00 & 0,16 & \\
\hline Ni9 & 1,59 & 0,53 & 0,19 & $\mathrm{~N}$ & 0,00 & 1,00 & 0,00 & 1,00 & 0,29 \\
\hline & & & & DoR & 0,00 & 0,22 & 0,00 & 0,15 & \\
\hline Ocotea catharinensis & 1,56 & 0,52 & 0,18 & $\mathrm{~N}$ & 0,00 & 1,00 & 0,00 & 1,00 & 0,29 \\
\hline & & & & DoR & 0,00 & 0,17 & 0,00 & 0,12 & \\
\hline Ni13 & 1,56 & 0,52 & 0,18 & $\mathrm{~N}$ & 0,00 & 1,00 & 0,00 & 1,00 & 0,29 \\
\hline & & & & DoR & 0,00 & 0,17 & 0,00 & 0,12 & \\
\hline $\mathrm{Ni7}$ & 1,53 & 0,51 & 0,17 & $\mathrm{~N}$ & 0,00 & 1,00 & 0,00 & 1,00 & 0,29 \\
\hline & & & & DoR & 0,00 & 0,15 & 0,00 & 0,10 & \\
\hline Ni5 & 1,53 & 0,51 & 0,16 & $\mathrm{~N}$ & 1,00 & 0,00 & 0,00 & 1,00 & 0,05 \\
\hline & & & & DoR & 1,16 & 0,00 & 0,00 & 0,10 & \\
\hline Ni28 & 1,53 & 0,51 & 0,16 & $\mathrm{~N}$ & 0,00 & 1,00 & 0,00 & 1,00 & 0,29 \\
\hline & & & & DoR & 0,00 & 0,14 & 0,00 & 0,09 & \\
\hline Calycophyllum spruceanum & 1,53 & 0,51 & 0,16 & $\mathrm{~N}$ & 0,00 & 1,00 & 0,00 & 1,00 & 0,29 \\
\hline & & & & DoR & 0,00 & 0,12 & 0,00 & 0,08 & \\
\hline Ni22 & 1,53 & 0,51 & 0,16 & $\mathrm{~N}$ & 0,00 & 1,00 & 0,00 & 1,00 & 0,29 \\
\hline & & & & DoR & 0,00 & 0,12 & 0,00 & 0,08 & \\
\hline $\mathrm{Ni25}$ & 1,51 & 0,50 & 0,15 & $\mathrm{~N}$ & 0,00 & 1,00 & 0,00 & 1,00 & 0,29 \\
\hline & & & & DoR & 0,00 & 0,11 & 0,00 & 0,07 & \\
\hline *** Total & 300 & 100,00 & 100,00 & $\mathrm{~N}$ & 59,00 & 326,00 & 42,00 & 427,00 & 100,00 \\
\hline & & & & DoR & 100,00 & 100,00 & 100,00 & 100,00 & \\
\hline
\end{tabular}

\section{CONCLUSÃo}

Com a realização do presente trabalho pode-se conhecer a composição florística e fitossociológica das espécies arbóreas do fragmento de Floresta Estacional Semidecidual, situado no município de São João Evangelista-MG.

De acordo com os valores obtidos observou-se tendência a uniformidade da florística do componente arbóreo.

\section{REFERÊNCIAS BIBLIOGRÁFICAS}

ALMEIDA JÚNIOR, J. S. Florística e Fitossociologia de Fragmentos da Floresta Estacional Semidescidual, Viçosa, Minas Gerais. Viçosa, MG: UFV, 1999.

AMBIENTE BRASIL. Portal de notícias e conteúdo sobre meio ambiente do Brasil. Disponível em $<$ http://www.ambientebrasil. com.br/composer.php3?base=./natural/index.html\&conteudo=./natural/clima.html $>$. Acesso em outubro. 2008. 
CIENTEC (Consultoria e Desenvolvimento de Sistemas Ltda.), Mata Nativa - Sistema para Análise Fitossociológica e elaboração de planos de manejo de florestas nativas. São Paulo, 2002, 126p.

CUSTÓDIO FILHO, A.; FRANCO, G.A.D.C.; DIAS, A.C. Composição florística de um trecho de floresta pluvial atlântica, em regeneração natural após desmatamento diferenciado em Pariqüera-açu, SP - Brasil.

Revista do Instituto Florestal, São Paulo, v.6, n. único, p.87-98, 1994.

ESPÍRITO - SANTO, F. B. ; OLIVEIRA - FILHO, A. T. . Estudo do efeito da fragmentação florestal em um remanescente de floresta semidecidual montana, no campus da Universidade Federal de Lavras UFLA - MG. Revista Brasileira de Botânica, São Paulo, v. Prelo, 2001.

CETEC - FUNDAÇÃO CENTRO TECNOLOGICO DE MINAS GERAIS. 1983. Diagnóstico ambiental do estado de Minas Gerais. CETEC, Belo Horizonte.

GILHUIS, J. P. Vegetation survey of the Parque Florestal Estadual do Rio Doce, MG, Brazil. 1986. 86 p. Dissertação (Mestrado em Ciência Florestal) - Universidade Federal de Viçosa, Viçosa.

GOOGLE EARTH. Disponível em: < http://www. googleearth.com>. Acesso em: 20 out. 2010.

GUIMARÃES, J. C. C.; BERG, E. V. D.; CASTRO, G. C.; MACHADO, E. L. M.; OLIVEIRA-FILHO, A. T. Dinâmica do componente arbustivo-arbóreo de uma floresta de galeria aluvial no planalto de Poços de Caldas, MG, Brasil. Revista Brasil. Bot., V.31, n.4, p.621-632, 2008.

IEF. PORTARIA No 191, DE 16 DE SETEMBRO DE 2005. Disponível em: $<$ http:// servicos.meioambiente.mg.gov.br/legislacao/ legislacao.asp>. Acesso em outubro. 2008.
LEITÃO-FILHO, H. F. Aspectos taxonômicos das florestas do Estado de São Paulo. Silvicultura em São Paulo, v. 16: p. 197-206, 1982.

LEITÃO-FILHO, H. F. A flora arbórea da Serra do Japi. In História natural da Serra do Japi - ecologia e preservação de uma área florestal no sudeste do Brasil (L.P.C. Morellato, org.). EDUNICAMP, Campinas, p. 40-62, 1992.

OLIVEIRA-FILHO, A. T.; MACHADO, J. N. M. Composição florística de uma floresta semidecídua montana, na Serra de São José, Tiradentes, Minas Gerais. Acta Botanica Brasilica 7(2), p. 71-88, 1993.

OLIVEIRA-FILHO, A. T., VILELA, E. A., GAVILANES, M. L., CARVALHO, D. A. Comparasion of the woody flora and soils of six áreas of montane semideciduous Forest in Southern Minas Gerais, Brasil. Edinburgh Journal of Botany, Edinburgh, v. 51, n. 4, p. 524-558, 1994.

PAES, J. B.; MORAIS, V. M.; LIMA, C. R. Resistência natural de nove espécies de madeiras do semi-árido brasileiro a fungos causadores da podridão-mole. Revista Árvore, v. 29, n. 3, p. 365-371, 2005.

PAULA, J.E.; ENCINAS, J.I.; PEREIRA, B.A.S. Inventário de um hectare de mata ripária. Pesquisa Agropecuária Brasileira, Brasília, v. 28, n. 2, p. 143-152. 1993.

PROCÓPIO, A. L. F. Portalsjevangelista: Site criado para São João Evangelista-MG, como fonte de informação, lazer e cultura.

$<$ http://www.portalsjevangelista.com/dados gerais.asp>. Acesso em outubro. 2008.

SCHIAVINI, I. Estrutura das comunidades arbóreas de mata de galeria da Estação Ecológica do Panga (Uberlândia, MG). Tese de Doutorado, Universidade Estadual de Campinas, Campinas, SP. 1992. 
SCOLFORO, J. R. S.; MELLO, J. M. Inventário Florestal. Lavras-MG: UFLA/FAEPE, 561 p., 2006.

SILVA JÚNIOR, M. C. Fitossociologia e estrutura diamétrica na mata de Galeria do Pitoco, na reserva ecológica do IBGE, DF. Revista Cerne, v. 11, n. 2, p. 147-158, abr./jun. 2005. Disponível em: <http://www.ipef.br/ publicacoes/scientia/nr68/cap07.pdf > . Acesso em: agosto, 2008.

SOARES, C. P. B.; PAULA NETO, F.; SOUZA, A. L. Dendrometria e Inventário Florestal. Viçosa-MG: UFV, 276p., 2006.

SOUZA, F. N.; ARAÚJO, E. J. G.; MELLO, J. M.; SOLFORO, J. R. S.; SILVA, C. P. C. Composição florística e estrutura de dois fragmentos de floresta estacional semidecidual na Bacia do Rio Grande, Minas gerais. Revista Brasileira de Biociências, Porto Alegre, RS, v. 5, supl. 2, p. 183-185, jul. 2007.
VILELA, E.A.; OLIVEIRA FILHO, A.T.; GAVINALES, M.L.; CARVALHO, D.A. Espécies de matas ciliares com potencial para estudos de revegetação no alto Rio Grande, sul de minas. Revista Árvore, Viçosa, v. 17, n.2, p. 117-128. 1993.

WERNECK , H. A.; BOALENTE, R.; PIMENTA, A.; TOSTES, R. B. Florística e fitossociologia de um componente arbóreo da mata do Ginásio São José - UBÁ, Minas Gerais - Projeto piloto de contensão de erosão da Bacia do Paraíba do sul. Anais do VII Congresso de Ecologia do Brasil, Caxambu - MG, 23 a 28 de setembro. 2007. 